\title{
The Pathophysiology of Low Systemic Blood Flow in the Preterm Infant
}

\author{
Martin Kluckow* \\ Department of Neonatology, Royal North Shore Hospital, University of Sydney, Sydney, NSW, Australia
}

Assessment and treatment of the VLBW infant with cardiovascular impairment requires understanding of the underlying physiology of the infant in transition. The situation is dynamic with changes occurring in systemic blood pressure, pulmonary pressures, myocardial function, and ductal shunt in the first postnatal days. New insights into the role of umbilical cord clamping in the transitional circulation have been provided by large clinical trials of early versus later cord clamping and a series of basic science reports describing the physiology in an animal model. Ultrasound assessment is invaluable in assessment of the physiology of the transition and can provide information about the size and shunt direction of the ductus arteriosus, the function of the myocardium and

OPEN ACCESS

Edited by:

Eugene Dempsey,

University College Cork, Ireland

Reviewed by:

Anup C. Katheria,

Sharp Mary Birch Hospital for

Women \& Newborns,

United States

Kai König,

Mercy Hospital for Women,

Australia

*Correspondence:

Martin Kluckow

martin.kluckow@sydney.edu.au

Specialty section:

This article was submitted

to Neonatology,

a section of the journal

Frontiers in Pediatrics

Received: 18 December 2017

Accepted: 31 January 2018

Published: 16 February 2018

Citation:

Kluckow M (2018) The

Pathophysiology of Low Systemic Blood Flow in the Preterm Infant.

Front. Pediatr. 6:29.

doi: 10.3389/fped.2018.00029 its filling as well as measurements of the cardiac output and an estimate of the state of peripheral vascular resistance. This information not only allows more specific treatment but it will often reduce the need for treatment.

Keywords: preterm, neonate, hypotension, hemodynamics, superior vena cava

\section{INTRODUCTION}

The cardiovascular system of the fetus is adapted to an in utero environment that is constant and stable with the low resistance placenta being a key part of the hemodynamic equilibrium. The determinants of cardiac output are maintained in equilibrium without interference from external factors. Postnatal factors that can affect the cardiovascular function of the VLBW infant include perinatal asphyxia, sepsis, positive pressure respiratory support, variable carbon dioxide levels, and the time of clamping of the umbilical cord. During the immediate transitional period, these factors may alter preload, and change afterload at a time of rapid transition from the fetal circulation, characterized by low systemic vascular resistance, to the postnatal neonatal circulation with higher peripheral vascular resistance. The predominantly systemic to pulmonary shunts, occurring at atrial and ductal level through persisting fetal channels, can further reduce potential systemic blood flow (SBF) (Figure 1).

\section{DEFINITION OF HYPOTENSION}

Hypotension can be defined in two ways-physiologically or population based. The physiological definition is the blood pressure value where autoregulation of vital organ (brain) blood flow is reduced or lost with an impairment of adequate delivery of oxygen to the organs and tissues. If the blood pressure further decreases (and no treatment is initiated) it will eventually reach a "functional threshold" when neuronal function is impaired, and then finally an "ischemic threshold" which may result in tissue injury with likely permanent organ damage (1). From a clinical view point, neither of these limits have been well defined in the premature infant in the immediate postnatal period (2). 


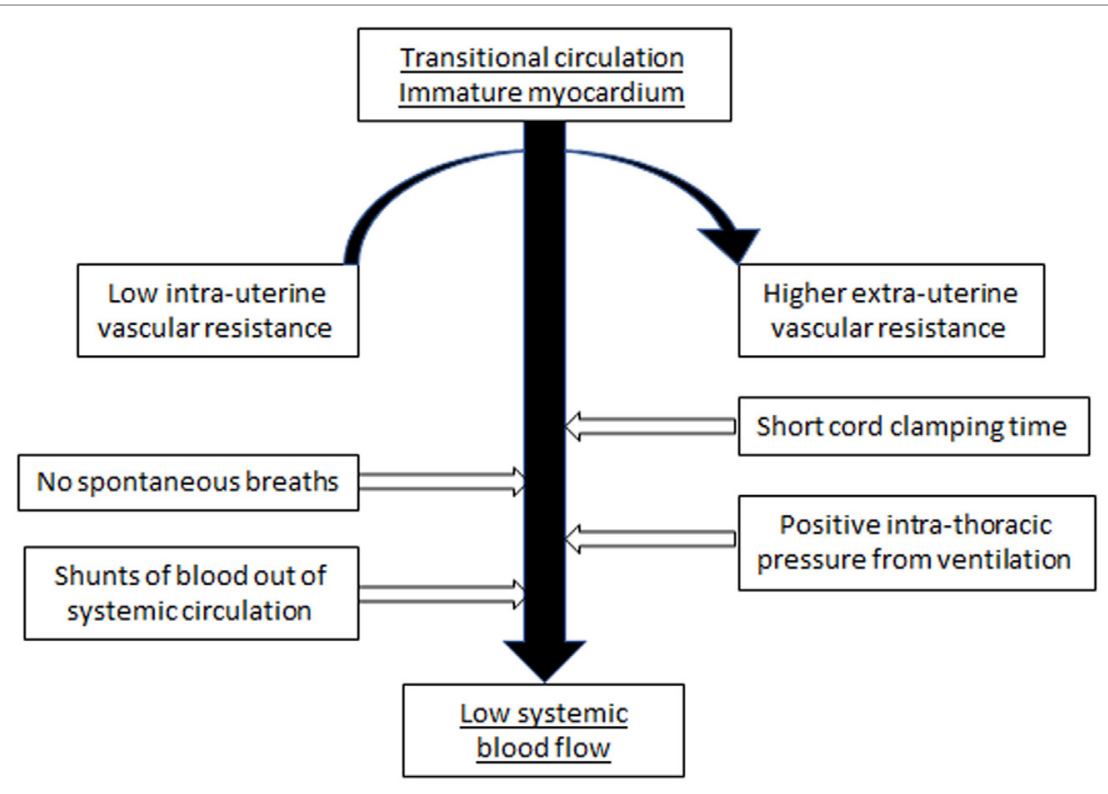

FIGURE 1 | Suggested model of how the various external and internal influences on the cardiovascular system of the VLBW infant can result in low systemic blood flow.

Low blood pressure may also be defined as population based. One definition is a mean blood pressure (MBP) less than $30 \mathrm{~mm} \mathrm{Hg}$ in any gestation infant in the first postnatal days. This definition relates to previously observed pathophysiologic associations between cerebral injury (white matter damage, periventricular leukomalacia, and/or peri/intraventricular hemorrhage) and MBP less than $30 \mathrm{~mm} \mathrm{Hg}$ at any time point in the first few postnatal days (3) and on more recent data aimed at maintenance of cerebral blood flow (CBF) measured by near-infrared spectroscopy $(4,5)$ Although the tenth centile for infants of all gestational ages by the third postnatal day is at or above $30 \mathrm{~mm} \mathrm{Hg}$, in more immature infants the 10th centile of MBP is lower than $30 \mathrm{~mm} \mathrm{Hg}$ during the first 3 days (6). Another population based definition is a MBP less than the GA in weeks during the first postnatal days, which relates to the 10th centile for age in tables of normative data $(6,7)$. This statistical definition has been supported by guidelines for blood pressure management by several professional bodies (8). This definition is relevant mainly in the first $24-48 \mathrm{~h}$ of extrauterine life-after which time there is a gradual increase in the expected MBP such that most premature infants have a MBP $>30 \mathrm{~mm} \mathrm{Hg}$ and thus above their gestational age by postnatal day 3 (7). More recent cohorts of neonates have been published defining population based norms of blood pressure in the modern era of neonatal intensive care $(9,10)$.

\section{THE TRANSITIONAL CIRCULATION IN THE PRETERM INFANT}

The preterm infant frequently has a failure of complete closure of both fetal communications, probably due to immaturity of the structural mechanisms involved $(11,12)$. The persistence of fetal channels in the setting of decreasing pulmonary pressures leads to blood flowing preferentially from the aorta to pulmonary artery resulting in a relative loss of blood from the systemic circulation and overloading of the pulmonary circulation. The myocardium attempts to compensate by increasing the total cardiac output (13). A significant proportion of this increased blood flow passes through the ductus arteriosus (14), thus augmenting pulmonary blood flow. Early ductal constriction is variable, with some infants having a closed/small ductus arteriosus shortly after birth while others initially constrict, followed by an increase in size of the ductus and others demonstrate a persistent large ductus arteriosus with no evidence of any early constriction. In these infants with a wider open patent ductus arteriosus (PDA) and decreasing pulmonary pressures, there can be a rapid increase in ductal shunt, resulting in pulmonary blood flow more than twice the SBF in the first few postnatal hours (15). Excessive pulmonary blood flow can have clinical consequences, which include decreased systemic blood pressure and blood flow, increases in ventilatory requirements, or even pulmonary hemorrhagic edema and eventually pulmonary hemorrhage $(15,16)$.

Ventricular systolic function is defined by preload (filling of the ventricle with blood prior to contraction), contractility (intrinsic ability of myocardial fibers to contract), and afterload (combined resistance of the blood, the ventricular walls and the vascular beds). The preterm myocardium is less mature than the term infant with histological differences including less numbers of mitochondria and subsequently less energy stores (17). This results in limitation in the ability to respond to changes in the components of the cardiac output, in particular the afterload $(18,19)$. The myocardium of the preterm infant has a reduced ability to respond to postnatal period stress including increases in peripheral vascular resistance or afterload (20) with small 
changes having profound effects, particularly in the setting of inadequate preload or impaired contractility (18). Oxygen delivery is primarily related to the oxygen carrying capacity of the blood, oxygen content, and the volume of blood flow delivered to the organ, and this may be inadequate where there is cardiovascular impairment (21).

\section{DETERMINANTS OF THE BLOOD PRESSURE IN THE PRETERM INFANT}

Arterial blood pressure is the product of cardiac output and the peripheral vascular resistance. The main influences on cardiac output are preload or blood volume and myocardial contractility. Peripheral vascular resistance is determined by vascular tone, which in the presence of an unconstricted ductus arteriosus includes not only the systemic peripheral vascular resistance but also pulmonary vascular resistance. Myocardial contractility is difficult to assess in the newborn as the accepted measures of contractility in the adult, such as the echocardiographic measure of fractional shortening, are adversely influenced by the asymmetry of the ventricles caused by the in utero right ventricular dominance. Newer techniques such as tissue Doppler imaging may overcome these limitations (20).

In the preterm neonate with a closed ductus arteriosus during the first $24-48 \mathrm{~h}$, the relationship between MBP and cardiac output is poor (22). Many hypotensive preterm infants have a normal or high left ventricular output, thus compensating for reduced systemic blood pressure (22-24). One of the reasons for this apparent paradox is the presence of a hemodynamically significant ductus arteriosus, which causes an increase in left ventricular output while also causing a reduction in the overall systemic vascular resistance. Variations in the peripheral vascular resistance may cause a change in the underlying cardiac output that does not affect the blood pressure. This phenomenon makes it possible for two infants with the same blood pressure to have markedly different cardiac outputs.

\section{Gestational Age and Postnatal Age}

All population-based collections of blood pressure data show that there is a major influence of gestational age on the blood pressure, with the most immature infants having the lowest MBP on the first day of life. Similarly, population based blood pressure nomograms show a significant influence of postnatal age on the blood pressure with a progressive increase in MBP each postnatal day $(6,25)$. This is probably related to changes in vascular tone mediated by humoral and sympathetic nervous system mediators, in addition to maturation of the fetal/neonatal myocardium such that it can respond better to afterload $(19,20)$.

\section{Blood Loss}

Acute blood loss in the preterm infant is unusual and can result from prenatal events such as feto-maternal hemorrhage, antepartum hemorrhage, or twin-twin transfusion syndrome, intrapartum events such as a tight nuchal cord with differential vessel constriction resulting in an imbalance between blood flow to and from the fetus or postnatally from a large subgaleal hematoma or hemorrhage into an organ such as the liver or brain. Acute blood loss can result in significant hypotension but due to the immediate compensatory mechanisms of the cardiovascular system, these effects may be delayed and present only when the phase of decompensation occurs.

\section{Timing of Umbilical Cord Clamping}

Both the volume of placental transfusion and the normal sequence of the transition can be affected by the timing of clamping of the umbilical cord with later clamping being associated with a smoother hemodynamic transition (in a preterm sheep model) (26). A delay in clamping the umbilical cord from 1 to $3 \mathrm{~min}$ is also associated with increased systemic blood pressure and a decreased need for cardiovascular support and blood transfusions as demonstrated in the systematic review of the effects of delayed cord clamping/placental transfusion (27). The largest RCT of delayed cord clamping to date (1,566 babies) has just been published (28) and a smaller subset of this trial had advanced cardiovascular monitoring and blood pressure measurements (29) which showed no increase in rates of treated hypotension in the early clamped arm.

\section{Positive Pressure Ventilation}

Many preterm infants are exposed to positive pressure respiratory support in the first postnatal days, although there has been a progressive reduction in the use of mechanical ventilation, particularly as an early first line treatment. Positive endexpiratory pressure is often utilized to reduce the atelectasis resulting from collapse of unstable alveoli when surfactant is lacking, particularly in more immature infants. Function can be impaired by a reduction in the preload from reduced systemic or pulmonary venous return, and/or direct compression of cardiac chambers also resulting in a reduced stroke volume or an increase in afterload. In longitudinal clinical studies of blood pressure and blood flow, mean airway pressure has a consistently negative influence on both MBP and SBF (22, 30-32). More recent clinical studies have failed to demonstrate clinically relevant decreases in blood flow in the conventional range of pressure support (33-35).

\section{Patent Ductus Arteriosus}

The classic signs of a PDA with increased pulse pressure and evidence of diastolic runoff have resulted in the perception that a PDA is mainly associated with a low diastolic blood pressure. However, several studies have suggested that the PDA can also be associated with both low diastolic and low systolic blood pressure. Thus, a PDA is one of the possible causes of systemic hypotension and PDA assessment should be part of the investigation of hypotension in the first days of life $(36,37)$. Clinical assessment of a PDA in the first postnatal days is difficult and cardiac ultrasound is often required for early diagnosis (38). The clinical signs of a PDA including systolic murmur, high volume pulses, and a hyperdynamic precordium only become easily detectable after day 3 of postnatal life (38). This increasing left to right shunt may also result in an increasing systemic to pulmonary shunt which can manifest as reduced blood pressure and/or SBF, even in the first few days of life. 


\section{ASSESSMENT OF CARDIOVASCULAR COMPROMISE IN THE PRETERM INFANT}

The assessment of cardiovascular adequacy and thus tissue oxygen delivery in the VLBW infant is more of a challenge than in infants and adults. Assessment often consists of a mainly clinical appraisal of the perfusion via capillary refill time (CRT) and urine output and the intermittent documentation of the pulse rate and blood pressure. The acid-base balance and evidence of lactic acidosis are further important adjuncts to this assessment but, unless serum lactate levels are serially monitored, monitoring changes in $\mathrm{pH}$ and base deficit may be misleading due to the increased bicarbonate losses through the immature kidneys. Additionally, these measures tend to reflect cardiovascular changes some hours previously rather than the current circumstances.

\section{Capillary Refill Time}

Capillary refill time (CRT) is a widely utilized proxy of both cardiac output and peripheral resistance in adults and older children, as well as in neonates where normal values have been documented (39). A study investigating the relationship between a measure of SBF and CRT in VLBW infants showed that a CRT of $\geq 3$ s had only $55 \%$ sensitivity and $81 \%$ specificity for predicting low SBF. However, a markedly increased CRT of $4 \mathrm{~s}$ or more was more closely correlated with low blood flow states (40).

\section{Urine Output}

Urine output is useful in the assessment of cardiovascular wellbeing in the adult; however, the immature renal tubule in VLBW infants is inefficient at concentrating the urine and therefore has an impaired capacity to appropriately adjust urine osmolality and flow in the face of high serum osmolality (41). Even if the glomerular filtration rate is decreased markedly, there can be little change in urine output. Accurate measurement of urine output is not easy in VLBW infants, requiring collection via a urinary catheter or via a collection bag, both techniques being invasive.

\section{Pulse Rate}

Preterm infants generally have a faster baseline heart rate and immature myocardium and autonomic nervous system such that the cardiovascular response to hypovolemia is different to that in older children and adults. A rising pulse rate is usually indicative of hypovolemia in the adult. The mechanism relies on a mature autonomic nervous system, with detection of reduced blood volume and then blood pressure via baroreceptors and a subsequent increase in the heart rate in an attempt to sustain appropriate cardiac output. Heart rate is affected by many things in the immediate postnatal period so it cannot be relied upon as an accurate assessment of cardiovascular status.

\section{Blood Pressure}

Arterial blood pressure can be measured invasively using either an umbilical artery catheter placed in the descending aorta or an arterial catheter placed in a peripheral artery such as the radial or posterior tibial artery. There is good correlation between blood pressure obtained via a peripheral artery catheter versus that obtained via the umbilical artery (42). The agreement between direct and indirect (noninvasive) measures of blood pressure is generally also good (43-48). However, the noninvasive technique is more problematic in the preterm infant as it is more dependent on choice of the appropriate cuff size and is non-continuous $(49,50)$. With the increased use of non-invasive respiratory support even in the smallest infants, access to invasive blood pressure is becoming less common resulting in the need for other ways to assess perfusion and cardiovascular adequacy. There is an increasing tendency to utilize non-invasive BP measurement in our unit as the perceived risks of arterial lines are balanced with the decreasing incidence of hypotension in even the smallest babies.

\section{Metabolic Acidosis/Lactic Acidosis}

When oxygen delivery to organs is less than organ oxygen requirements and the compensatory mechanisms are fully utilized, there is a change to anaerobic metabolism at the cellular level. As adequate cardiovascular function is a key part of oxygen delivery, reduced SBF may result in increasing serum lactate levels. A combined lactate value of more than $4 \mathrm{mmol}$ with prolonged CRT more than $4 \mathrm{~s}$ predicts low SBF with $97 \%$ specificity (51). There are associations between raised serum lactate levels and illness severity and mortality in ventilated neonates, specifically those with respiratory distress syndrome (52-59). The normal lactate level is $<2.5 \mathrm{mmoL} / \mathrm{L}$, and as the serum lactate level increases above this threshold, there is an increase in mortality $(57,58)$.

\section{Cardiac Output and SBF}

The size of neonates, particularly those less than 30 weeks gestation, with the associated difficulty of placing intracardiac catheters, has meant that the use of more invasive hemodynamic measures such as pulmonary artery thermodilution and mixed venous oxygen saturation monitoring has not been possible. Another issue specific to premature infants is the potential inaccuracy of the dye dilution and thermodilution method in the presence of intracardiac shunts through the ductus arteriosus and the foramen ovale. Noninvasive methods of measuring cardiac output, particularly using Doppler ultrasound, have become more popular, aided by improvements in picture resolution and reductions in ultrasound transducer size. Newer approaches such as impedance electrical cardiometry, which allows continuous beat-to-beat assessment of cardiac output are now becoming available and may facilitate the continuous collection of cardiac output for real-time decision making (60).

Normal MBP does not mean normal LV output or cerebral blood flow in preterm infants, including in those who have a closed ductus arteriosus $(22,24,61)$. This observation has led to the development of bedside cardiac ultrasound techniques directed at measuring cardiac output/SBF and assessing the function of the heart as well as allowing assessment of the size of fetal shunts (62). Assessment of SBF in the preterm infant is problematic due to the persistence of the fetal shunts ( $\mathrm{PFO}$ and PDA). Increased blood flow through the PDA (left to right ductal shunt) results in an increased LV output as the output is measured at the aortic valve, prior to the PDA connection to the systemic circulation. Similarly, left to right shunt through a patent foramen 
ovale results in an increased RV output as the output is measured at the pulmonary valve, after the point where the PFO shunt combines with the systemic venous return (15). Thus, neither LV nor RV output are truly representative of SBF. To overcome this limitation, we developed the measure of superior vena cava (SVC) flow which assesses cardiac input and is unaffected by the fetal shunts (63).

Low SBF, as measured via SVC flow or return of blood from the upper body to heart (63), is seen in up to $35 \%$ of VLBW infants in the first $24 \mathrm{~h}$. Not all of these infants will have hypotension initially, though many (up to 80\%) will develop it (63). More recent studies of the incidence of low SVC flow show a reduced incidence (18-21\% of ELBW infants) possibly reflecting changes in delivery room care, respiratory management, and perhaps fluid management of the neonate $(29,64,65)$. SBF may fall dramatically in extremely premature infants during the first hours after delivery and this reduction in flow is usually associated with an increase in peripheral vascular resistance/afterload (19). A substantial proportion of these infants will initially have a "normal" blood pressure (i.e., they are in "compensated shock"). Hypotension may also be associated with normal or even a high SBF as frequently occurs in

\section{REFERENCES}

1. McLean CW, Noori S, Cayabyab R, Seri I. Cerebral circulation and hypotension in the premature infant-diagnosis and treatment. In: Perlman JM, editor. Questions and Controversies in Neonatology - Neurology. 2nd ed. Philadelphia: Saunders/Elsevier (2011). p. 3-27.

2. Seri I. Circulatory support of the sick preterm infant. Semin Neonatol (2001) 6(1):85-95. doi:10.1053/siny.2000.0034

3. Miall-Allen VM, de Vries LS, Whitelaw AG. Mean arterial blood pressure and neonatal cerebral lesions. Arch Dis Child (1987) 62(10):1068-9. doi:10.1136/ adc.62.10.1068

4. Tsuji M, Saul JP, du PA, Eichenwald E, Sobh J, Crocker R, et al. Cerebral intravascular oxygenation correlates with mean arterial pressure in critically ill premature infants. Pediatrics (2000) 106(4):625-32. doi:10.1542/peds.106.4.625

5. Munro MJ, Walker AM, Barfield CP. Hypotensive extremely low birth weight infants have reduced cerebral blood flow. Pediatrics (2004) 114(6):1591-6. doi:10.1542/peds.2004-1073

6. Watkins AM, West CR, Cooke RW. Blood pressure and cerebral haemorrhage and ischaemia in very low birthweight infants. Early Hum Dev (1989) 19(2):103-10. doi:10.1016/0378-3782(89)90120-5

7. Hegyi T, Carbone MT, Anwar M, Ostfeld B, Hiatt M, Koons A, et al. Blood pressure ranges in premature infants. I. The first hours of life. J Pediatr (1994) 124(4):627-33. doi:10.1016/S0022-3476(05)83146-4

8. Development of audit measures and guidelines for good practice in the management of neonatal respiratory distress syndrome. Report of a joint working group of the British Association of Perinatal Medicine and the research unit of the Royal College of Physicians. Arch Dis Child (1992) 67(10):1221-7.

9. Laughon M, Bose C, Allred E, O'Shea TM, Van Marter LJ, Bednarek F, et al. Factors associated with treatment for hypotension in extremely low gestational age newborns during the first postnatal week. Pediatrics (2007) 119(2):273-80. doi:10.1542/peds.2006-1138

10. Batton B, Li L, Newman NS, Das A, Watterberg KL, Yoder BA, et al. Evolving blood pressure dynamics for extremely preterm infants. J Perinatol (2014) 34(4):301-5. doi:10.1038/jp.2014.6

11. Evans N, Iyer P. Longitudinal changes in the diameter of the ductus arteriosus in ventilated preterm infants: correlation with respiratory outcomes. Arch Dis Child Fetal Neonatal Ed (1995) 72(3):F156-61. doi:10.1136/fn.72.3.F156

12. Seidner SR, Chen YQ, Oprysko PR, Mauray F, Tse MM, Lin E, et al. Combined prostaglandin and nitric oxide inhibition produces anatomic remodeling and closure of the ductus arteriosus in the premature newborn baboon. Pediatr Res (2001) 50(3):365-73. doi:10.1203/00006450-200109000-00012 the preterm infant with persisting hypotension after the first postnatal days or those with "hyperdynamic" sepsis (66). These infants generally have low systemic vascular resistance with peripheral vasodilation.

\section{CONCLUSION}

Appropriate assessment and treatment of the preterm infant with cardiovascular impairment or shock requires the clinician to obtain adequate information about the etiology and underlying physiologic determinants of the condition. Ultrasound evaluation can provide information about the size and shunt direction of the ductus arteriosus, the function of the myocardium and its filling as well as a cross sectional measurement of the cardiac output. This information is valuable in understanding underlying physiology and deciding on management strategies for newborn infants with cardiovascular instability and/or impairment.

\section{AUTHOR CONTRIBUTIONS}

This article was conceived and written by MK.

13. Agata Y, Hiraishi S, Oguchi K, Misawa H, Horiguchi Y, Fujino N, et al Changes in left ventricular output from fetal to early neonatal life. J Pediatr (1991) 119:441-5. doi:10.1016/S0022-3476(05)82060-8

14. Drayton MR, Skidmore R. Ductus arteriosus blood flow during first 48 hours of life. Arch Dis Child (1987) 62(10):1030-4. doi:10.1136/adc.62.10.1030

15. Kluckow M, Evans N. Low systemic blood flow in the preterm infant. Semin Neonatol (2001) 6(1):75-84. doi:10.1053/siny.2000.0035

16. Kluckow M, Evans N. Ductal shunting, high pulmonary blood flow, and pulmonary hemorrhage. J Pediatr (2000) 137(1):68-72. doi:10.1067/mpd.2000.106569

17. Kluckow M. Low systemic blood flow and pathophysiology of the preterm transitional circulation. Early Hum Dev (2005) 81(5):429-37. doi:10.1016/j. earlhumdev.2005.03.006

18. Teitel DF. Physiologic development of the cardiovascular system in the fetus. 2nd ed. In: Polin RA, Fox WW, editors. Fetal and Neonatal Physiology. Philadelphia: W. B Saunders Company (1998). p. 827-36.

19. Takahashi Y, Harada K, Kishkurno S, Arai H, Ishida A, Takada G. Postnatal left ventricular contractility in very low birth weight infants. Pediatr Cardiol (1997) 18(2):112-7. doi:10.1007/s002469900127

20. Breatnach CR, El-Khuffash A, James A, McCallion N, Franklin O. Serial measures of cardiac performance using tissue Doppler imaging velocity in preterm infants <29weeks gestations. Early Hum Dev (2017) 108:33-9. doi:10.1016/j. earlhumdev.2017.03.012

21. Weindling AM, Kissack CM. Blood pressure and tissue oxygenation in the newborn baby at risk of brain damage. Biol Neonate (2001) 79(3-4):241-5. doi:10.1159/000047099

22. Kluckow M, Evans N. Relationship between blood pressure and cardiac output in preterm infants requiring mechanical ventilation. J Pediatr (1996) 129(4):506-12. doi:10.1016/S0022-3476(96)70114-2

23. Lopez SL, Leighton JO, Walther FJ. Supranormal cardiac output in the dopamine- and dobutamine-dependent preterm infant. Pediatr Cardiol (1997) 18(4):292-6. doi:10.1007/s002469900177

24. Pladys P, Wodey E, Beuchee A, Branger B, Betremieux P. Left ventricle output and mean arterial blood pressure in preterm infants during the 1st day of life. Eur J Pediatr (1999) 158(10):817-24. doi:10.1007/s004310051213

25. Nuntnarumit P, Yang W, Bada-Ellzey HS. Blood pressure measurements in the newborn. Clin Perinatol (1999) 26(4):981-96.

26. Bhatt S, Polglase GR, Wallace EM, Te Pas AB, Hooper SB. Ventilation before umbilical cord clamping improves the physiological transition at birth. Front Pediatr (2014) 2:113. doi:10.3389/fped.2014.00113

27. Rabe H, Diaz-Rossello JL, Duley L, Dowswell T. Effect of timing of umbilical cord clamping and other strategies to influence placental transfusion at 
preterm birth on maternal and infant outcomes. Cochrane Database Syst Rev (2012) 8:CD003248. doi:10.1002/14651858.CD003248.pub3

28. Tarnow-Mordi W, Morris J, Kirby A, Robledo K, Askie L, Brown R, et al. Delayed versus immediate cord clamping in preterm infants. N Engl J Med (2017) 377(25):2445-55. doi:10.1056/NEJMoa1711281

29. Popat H, Robledo KP, Sebastian L, Evans N, Gill A, Kluckow M, et al. Effect of delayed cord clamping on systemic blood flow: a randomized controlled trial. J Pediatr (2016) 178(81-6):e2. doi:10.1016/j.jpeds.2016.08.004

30. Kluckow M, Evans N. Low superior vena cava flow and intraventricular haemorrhage in preterm infants. Arch Dis Child Fetal Neonatal Ed (2000) 82:188-94. doi:10.1136/fn.82.3.F188

31. Skinner JR, Boys RJ, Hunter S, Hey EN. Pulmonary and systemic arterial pressure in hyaline membrane disease. Arch Dis Child (1992) 67(4):366-73. doi:10.1136/adc.67.4_Spec_No.366

32. Evans N, Kluckow M. Early determinants of right and left ventricular output in ventilated preterm infants. Arch Dis Child Fetal Neonatal Ed (1996) 74(2):F88-94. doi:10.1136/fn.74.2.F88

33. Chang HY, Cheng KS, Lung HL, Li ST, Lin CY, Lee HC, et al. Hemodynamic effects of nasal intermittent positive pressure ventilation in preterm infants. Medicine (Baltimore) (2016) 95(6):e2780. doi:10.1097/MD. 0000000000002780

34. Beker F, Rogerson SR, Hooper SB, Wong C, Davis PG. The effects of nasal continuous positive airway pressure on cardiac function in premature infants with minimal lung disease: a crossover randomized trial. J Pediatr (2014) 164(4):726-9. doi:10.1016/j.jpeds.2013.10.087

35. de Waal KA, Evans N, Osborn DA, Kluckow M. Cardiorespiratory effects of changes in end expiratory pressure in ventilated newborns. Arch Dis Child Fetal Neonatal Ed (2007) 92(6):F444-8. doi:10.1136/adc.2006.103929

36. Evans N, Moorcraft J. Effect of patency of the ductus arteriosus on blood pressure in very preterm infants. Arch Dis Child (1992) 67:1169-73. doi:10.1136/ adc.67.10_Spec_No.1169

37. Sarkar S, Dechert R, Schumacher RE, Donn SM. Is refractory hypotension in preterm infants a manifestation of early ductal shunting? J Perinatol (2007) 27(6):353-8. doi:10.1038/sj.jp.7211749

38. Skelton R, Evans N, Smythe J. A blinded comparison of clinical and echocardiographic evaluation of the preterm infant for patent ductus arteriosus. J Paediatr Child Health (1994) 30:406-11. doi:10.1111/j.1440-1754.1994. tb00689.x

39. Strozik KS, Pieper CH, Roller J. Capillary refilling time in newborn babies: normal values. Arch Dis Child Fetal Neonatal Ed (1997) 76(3):F193-6. doi:10.1136/ fn.76.3.F193

40. Osborn DA, Evans N, Kluckow M. Clinical detection of low upper body blood flow in very premature infants using blood pressure, capillary refill time, and central-peripheral temperature difference. Arch Dis Child Fetal Neonatal Ed (2004) 89(2):F168-73. doi:10.1136/adc.2002.023796

41. Linshaw MA. Concentration of the urine. 2nd ed. In: Polin RA, Fox WW, editors. Fetal and Neonatal Physiology. Philadelphia: W.B. Saunders Company (1998). p. 1634-53.

42. Butt WW, Whyte HW. Blood pressure monitoring in neonates: comparison of umbilical and peripheral artery measurements. J Pediatr (1984) 105:630-2. doi:10.1016/S0022-3476(84)80437-0

43. Colan SD, Fujii A, Borow KM, MacPherson D, Sanders SP. Noninvasive determination of systolic, diastolic and end-systolic blood pressure in neonates, infants and young children: comparison with central aortic pressure measurements. Am J Cardiol (1983) 52(7):867-70. doi:10.1016/0002-9149 (83) $90430-7$

44. Emery EF, Greenough A. Non-invasive blood pressure monitoring in preterm infants receiving intensive care. Eur J Pediatr (1992) 151(2):136-9. doi:10.1007/BF01958960

45. Kimble KJ, Darnall RA Jr, Yelderman M, Ariagno RL, Ream AK. An automated oscillometric technique for estimating mean arterial pressure in critically ill newborns. Anesthesiology (1981) 54(5):423-5. doi:10.1097/00000542198105000-00016

46. Lui K, Doyle PE, Buchanan N. Oscillometric and intra-arterial blood pressure measurements in the neonate: a comparison of methods. Aust Paediatr J (1982) 18(1):32-4.

47. Park MK, Menard SM. Accuracy of blood pressure measurement by the Dinamap monitor in infants and children. Pediatrics (1987) 79(6):907-14.
48. O'Shea J, Dempsey EM, O'Shea J, Dempsey EM. A comparison of blood pressure measurements in newborns. Am J Perinatol (2009) 26(2):113-6. doi:10.1055/s-0028-1091391

49. Dannevig I, Dale HC, Liestol K, Lindemann R. Blood pressure in the neonate: three non-invasive oscillometric pressure monitors compared with invasively measured blood pressure. Acta Paediatr (2005) 94(2):191-6. doi:10.1080/08035250410023629

50. Konig K, Casalaz DM, Burke EJ, Watkins A. Accuracy of non-invasive blood pressure monitoring in very preterm infants. Intensive Care Med (2012) 38(4):670-6. doi:10.1007/s00134-012-2499-y

51. Miletin J, Pichova K, Dempsey EM. Bedside detection of low systemic flow in the very low birth weight infant on day 1 of life. Eur J Pediatr (2009) 168(7):809-13.

52. Cady LD Jr, Weil MH, Afifi AA, Michaels SF, Liu VY, Shubin H. Quantitation of severity of critical illness with special reference to blood lactate. Crit Care Med (1973) 1(2):75-80. doi:10.1097/00003246-197303000-00003

53. Peretz DI, Scott HM, Duff J, Dossetor JB, MacLean LD, McGregor M. The significance of lacticacidemia in the shock syndrome. Ann N Y Acad Sci (1965) 119(3):1133-41. doi:10.1111/j.1749-6632.1965.tb47467.x

54. Rashkin MC, Bosken C, Baughman RP. Oxygen delivery in critically ill patients. Relationship to blood lactate and survival. Chest (1985) 87(5):580-4. doi:10.1378/chest.87.5.580

55. Vincent JL, Dufaye P, Berre J, Leeman M, Degaute JP, Kahn RJ. Serial lactate determinations during circulatory shock. Crit Care Med (1983) 11(6):449-51. doi:10.1097/00003246-198306000-00012

56. Weil MH, Afifi AA. Experimental and clinical studies on lactate and pyruvate as indicators of the severity of acute circulatory failure (shock). Circulation (1970) 41(6):989-1001. doi:10.1161/01.CIR.41.6.989

57. Beca JP, Scopes JW. Serial determinations of blood lactate in respiratory distress syndrome. Arch Dis Child (1972) 47(254):550-7. doi:10.1136/adc.47.254.550

58. Deshpande SA, Platt MP. Association between blood lactate and acid-base status and mortality in ventilated babies. Arch Dis Child Fetal Neonatal Ed (1997) 76(1):F15-20. doi:10.1136/fn.76.1.F15

59. Graven SN, Criscuolo D, Holcomb TM. Blood lactate in the respiratory distress syndrome: significance in prognosis. Am J Dis Child (1965) 110(6):614-7. doi:10.1001/archpedi.1965.02090030642004

60. Noori S, Drabu B, Soleymani S, Seri I. Continuous non-invasive cardiac output measurements in the neonate by electrical velocimetry: a comparison with echocardiography. Arch Dis Child Fetal Neonatal Ed (2012) 97(5):F340-3. doi:10.1136/fetalneonatal-2011-301090

61. Kissack CM, Garr R, Wardle SP, Weindling AM. Cerebral fractional oxygen extraction in very low birth weight infants is high when there is low left ventricular output and hypocarbia but is unaffected by hypotension. Pediatr Res (2004) 55(3):400-5. doi:10.1203/01.PDR.0000111288.87002.3A

62. Kluckow M. Use of ultrasound in the haemodynamic assessment of the sick neonate. Arch Dis Child Fetal Neonatal Ed (2014) 99(4):F332-7. doi:10.1136/ archdischild-2013-304926

63. Kluckow M, Evans N. Superior vena cava flow in newborn infants: a novel marker of systemic blood flow. Arch Dis Child Fetal Neonatal Ed (2000) 82(3):F182-7. doi:10.1136/fn.82.3.F182

64. Miletin J, Dempsey EM. Low superior vena cava flow on day 1 and adverse outcome in the very low birthweight infant. Arch Dis Child Fetal Neonatal Ed (2008) 93(5):F368-71. doi:10.1136/adc.2007.129304

65. Paradisis M, Evans N, Kluckow M, Osborn D. Randomized trial of milrinone versus placebo for prevention of low systemic blood flow in very preterm infants. J Pediatr (2009) 154(2):189-95. doi:10.1016/j.jpeds.2008.07.059

66. de Waal K, Evans N. Hemodynamics in preterm infants with late-onset sepsis. J Pediatr (2010) 156(6):918-22,922.e1. doi:10.1016/j.jpeds.2009.12.026

Conflict of Interest Statement: The authors declare that the research was conducted in the absence of any commercial or financial relationships that could be construed as a potential conflict of interest.

Copyright (c) 2018 Kluckow. This is an open-access article distributed under the terms of the Creative Commons Attribution License (CC BY). The use, distribution or reproduction in other forums is permitted, provided the original author(s) and the copyright owner are credited and that the original publication in this journal is cited, in accordance with accepted academic practice. No use, distribution or reproduction is permitted which does not comply with these terms. 